\title{
Cardiac remodeling indicators in adolescent athletes
}

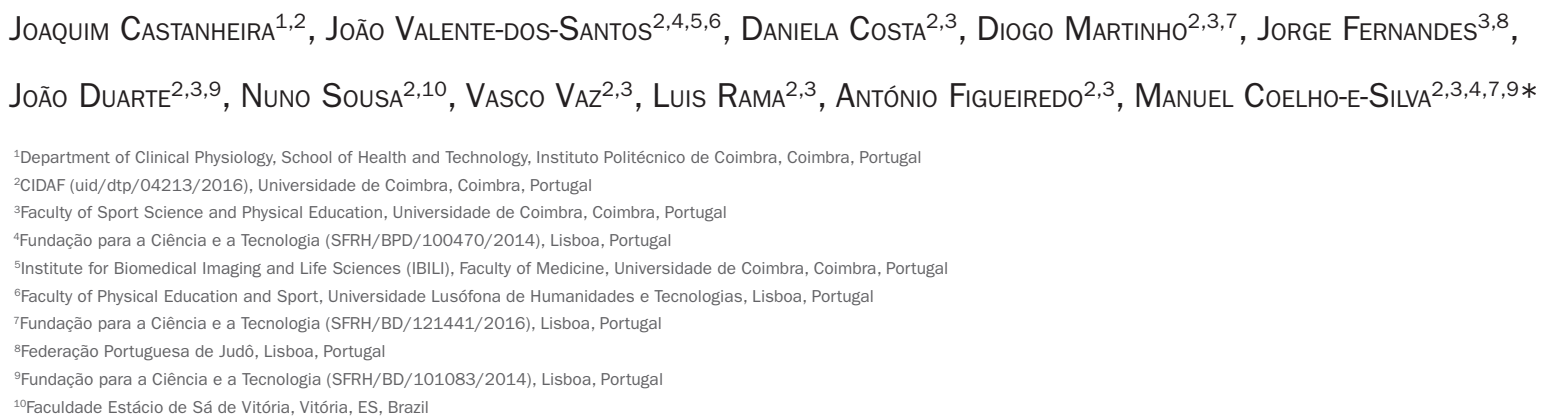

Study conducted by the UID/DTP/ $04213 / 2016$, Faculty of Sport Sciences and Physical Education, Universidade de Coimbra, and by the Department of Clinical Physiology, School of Health and Technology, Instituto Politécnico de Coimbra, Coimbra, Portugal

Article received: 10/26/2016 Accepted for publication: 12/1/2016

\section{SUMmARY}

\begin{abstract}
Objective: The idea that different sports and physical training type results in different cardiac adaptations has been widely accepted. However, this remodelling process among different sport modalities is still not fully understood. Thus, the current study aims to investigate the heart morphology variation associated with a set of different modalities characterized by distinct models of preparation and different methods and demands of training and completion.
\end{abstract}

Method: The sample comprises 42 basketball players, 73 roller hockey players, 28 judo athletes and 21 swimmers. Anthropometry was assessed by a single and experienced anthropometrist and the same technician performed the echocardiographic exams. Analysis of variance was used to study age, body size and echocardiograph parameters as well as different sport athlete's comparison.

Results: Basketball players are taller $(\mathrm{F}=23.448$; $\mathrm{p}<0.001$; $\mathrm{ES}-\mathrm{r}=0.553)$, heavier $(\mathrm{F}=6.702 ; \mathrm{p}<0.001 ; \mathrm{ES}-\mathrm{r}=0.334)$ and have a greater body surface area $(\mathrm{F}=11.896$; $\mathrm{p}<0.001 ; \mathrm{ES}-\mathrm{r}=0.427)$. Basketball and hockey players have larger left auricle diameters compared with judo athletes $(\mathrm{F}=3.865$; $\mathrm{p}=0.011$; $\mathrm{ES}-\mathrm{r}=0.316)$. Interventricular end-diastolic septal thickness $(\mathrm{F}=7.287$; $\mathrm{p}<0.001$; $\mathrm{ES}-\mathrm{r}=0.347)$ and left ventricular posterior wall thickness $(\mathrm{F}=8.038$; $\mathrm{p}<0.001$; $\mathrm{ES}-\mathrm{r}=0.362)$ of the judokas are smaller compared to the mean values of other sports participants. In addition, relative left parietal ventricular wall thickness is lower among swimmers compared with judokas ( $\mathrm{F}=4.127$; $\mathrm{p}=0.008$; ES-r=0.268).

Conclusion: The major contributors to changes in heart morphology are for the most part associated with sport-specific training and competition and the specific dynamics and adaptive mechanisms imposed by each sport.

Keywords: sports modalities, young athletes, echocardiography, left ventricle mass, body size, growth.

\section{INTRODUCTION}

The practice of sports offers a field of application to understand left ventricular (LV) cardiac remodeling, and is addressed in several studies ${ }^{1-3}$ pointing to the occurrence of concentric or eccentric hypertrophy depending on the modality practiced. However, athletes of the same modality, exposed to apparently similar training methodologies, evidence different cardiac remodeling processes, ${ }^{4}$ which implies the need to systematize knowledge across the vast spectrum of sports modalities and, within each of them, sex and age group by competitive level. Complementarily, no evidence of dichotomous cardiac adaptation was found among athletes of modalities with predominance of strength in the performance structure. ${ }^{5}$ The level of demand for the upper limbs is considered relevant in the process of cardiac remodeling. ${ }^{6}$

The average heart rate during a basketball game is around 171 beats per minute (bpm), although basketball 
is characterized by the existence of multiple and repeated episodes of high intensity and short duration exertion, ${ }^{7}$ and therefore is naturally regarded as a modality in which short-term energy demands predominate. Roller hockey, like most general sports games, has a complex structure, and it has been estimated that $71 \%$ of playing time $(n=14$, 20-32 years) includes intermittent high intensity activities, with an average heart rate of $163.5 \mathrm{bpm}$ and a reference lactate concentration of $4.20 \pm 0.95 \mathrm{mmol} / \mathrm{L} .{ }^{8}$ Despite some similarity between collective sports games in relation to the intermittent nature of the effort, roller hockey players are characterized by a predominance of musculoskeletal structures, ${ }^{9}$ as opposed to basketball, which attracts and promotes players of high stature. Modalities such as basketball, roller hockey and swimming were classified as sports with a low or moderate static component and high dynamic component, unlike judo, ${ }^{10}$ a modality in which repeated application of force and resistance is fundamental. ${ }^{11}$

Cardiac dimensions in children and young people were assumed to be directly proportional to height. ${ }^{12}$ In adolescent athletes, the available studies describe LV morphology and function as well as other cardiac parameters, ${ }^{1,13}$ but it is not always the interpretation of results relating to the relationships between sporting modalities, cavity dimensions and wall thickness that consider the additional effect attributable to body size, proportionality between trunk and limbs, and components of body composition. Our study examines the variation in the morphology of the heart associated to a set of sports modalities that are characterized by distinct long-term preparation models, different training and competition methodologies, and unique processes of selection and promotion of the most talented athletes. Our objective is to complement the studies that only proceed to the comparative analysis of athlete and non-athlete adolescents.

\section{Method}

\section{Study design and population}

Our study has a cross-sectional design and comprises young male athletes of various modalities $(n=164$, $15.28 \pm 0.76$ years): 42 basketball players (including 24 international players with participation in European championship games in their respective age groups), 73 hockey players (including 12 international and European champions in their respective age groups), 28 judokas (recruited to train with the national team in their respective age groups) and 21 swimmers (classified among the best swimmers of the Central Region of Portugal in their respective age groups). Several groups were formed ac- cording to age: $14.0-14.9$ years $(n=41) ; 15.0-15.9$ years $(n=100)$ and $16.0-16.9$ years $(n=23)$. All athletes were involved in federated sports for at least five years. None of the participants had evidence of organic disease or were under the effect of any active substance (medication or ergogenic supplementation). The study was approved by the Research Ethics Council and the Scientific Council of the FCDEF, University of Coimbra, and later by the Portuguese Foundation for Science and Technology (SFRH/PROTEC, process no. 67972/2010), in accordance with the principles of the Declaration of Helsinki. Participants and their representatives signed free and informed consent terms, ensuring the voluntary nature of the participation, as well as the confidentiality of the data.

\section{Whole body anthropometric measures}

Stature, body mass, and triceps subcutaneous and subscapular fat folds were evaluated by a single experienced anthropometrist, following the procedures described by Lohman et al. ${ }^{14}$ Stature was measured using a Harpenden stadiometer (model 98.603, Holtain Ltd, Crosswell, UK) and body mass using a SECA scale (model 770, Hanover, MD, United States). The folds of subcutaneous fat were measured using a Lange Skinfold Caliper adipometer (Beta Technology, Ann Arbor, MI, United States). Technical errors of measurement for height, body mass and folds of subcutaneous fat were $0.27 \mathrm{~cm}, 0.47 \mathrm{~kg}$, and $0.47-0.72 \mathrm{~mm}$, respectively. Percentage of fat mass was estimated according to the protocol by Slaughter et al. ${ }^{15}$ Subsequently, the absolute values for fat and lean mass were determined, in kilograms.

\section{Echocardiographic evaluation}

Echocardiogram is a noninvasive imaging test that allows information on cardiac structure and function to be obtained. It is the main source of information about cardiac adaptation in response to intensive training in athletes. ${ }^{16}$ To evaluate the cardiac morphology, a GE Vivid 3 echocardiograph was used, with a 1.5-3.6 MHz multifrequency probe (GE Vingmed Ultrasound, Horten, Norway). M-mode images were recorded from a parasternal long-axis view under direct visualization of the respective two-dimensional image. Dimensions and thicknesses were recorded at rest and parameters matching those of other similar studies performed with young athletes and adult athletes were selected., ${ }^{3,17}$ All echocardiographic examinations were performed by the same operator according to the recommendations of the American Society of Echocardiography (ASE) and the European Association of Echocardiography. ${ }^{18}$ The following diameter measure- 
ments were obtained: aortic root (AoR), left auricle (LA), left ventricular end-diastolic and end-systolic (LVED and LVES, respectively) diameters, and interventricular septal wall (IVSW) and left ventricular posterior wall (LVPW) thicknesses. Based on the previous dimensions, we calculated LV mass (LVM) using the ASE cube formula modified by Devereux et al. ${ }^{19}$ and measures of the predictors (IVSW, LVED and LVPW) expressed in millimeters:

$\operatorname{LVM}(\mathrm{g})=0.8 \times[1.04 \times(($ IVSW + LVED + LVPW $) 3-$ LVED3 $)]+0.6$

(Equation 1)

LVM was adjusted for body surface area (BSA, equation 2), allowing the calculation of the LV mass index $\left(\mathrm{g} / \mathrm{m}^{2}\right)$. Subsequently, left ventricular relative wall thickness (LVRPT) was determined as described by equation 3 to distinguish an $\mathrm{LV}$ concentric $(\geq 0.44)$ or eccentric $(<0.44)$ profile: ${ }^{1,13}$

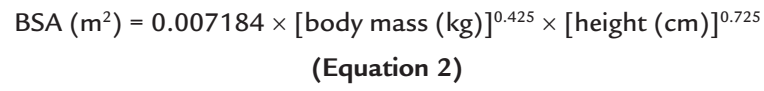

LV systolic function is translated by calculating the LV shortening (LVSF) and ejection fraction (LVEF). The shortening fraction uses the end-diastolic (LVED) and endsystolic (LVES) diameters, while the ejection fraction uses the end-diastolic (LVEDV) and the end-systolic (LVESV) volumes, respectively, according to equations 4 and $5:{ }^{18}$

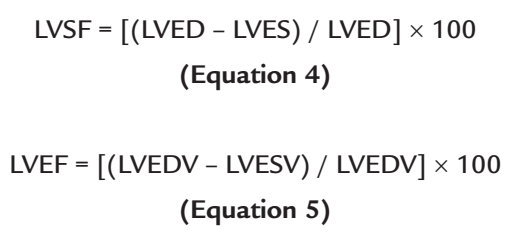

Data quality was assessed by determining the intraobserver variability using a random subgroup of 20 individuals (basketball players, $n=5$; hockey players, $n=5$; nonathletes, $n=10$ ) who were evaluated and reevaluated after one week by the same investigator, using the same equipment and following the procedures described above. The difference and percentage of difference between the two measurements were determined considering a $95 \%$ confidence interval for the dimensions of the cavities and cardiac thicknesses (0.02-0.17 mm, 95CI-1.95-2,28 mm). The parameters resulting from the evaluation of the previous measurements had a percentage of intraobserver variability ranging from 0.3 to $0.8 \%$ (95CI $-4.1-8.1 \%$ ).

\section{Statistical analysis}

Minimum, maximum, mean and standard deviation values were calculated for all variables. The absolute frequencies of adolescents divided by age group were calculated, considering also their classification by sport modality. We then used variance analysis (ANOVA) to study the age-related variation in body size measurements and parameters resulting from the echocardiographic evaluation, considering the entire sample. Finally, we used ANOVA once again to obtain a new comparison between athletes in different sports modalities, and covariance analysis (ANCOVA) adjusted for the additional effect of age, height and body mass. For the two analyzes of variance, we calculated the magnitude of the correlation effect (ES-r) estimated by the square root of the ratio of the $t$ value squared and the difference between $t$ value squared and the degrees of freedom. The level of significance was maintained at 5\%, as established for social and behavioral sciences. For statistical analysis of the data, we use Statistical Program for Social Sciences - SPSS software, version 19.0 for Windows.

\section{RESULTS}

The characteristics of the study's total sample are shown in Table 1. The dispersion measures given by the range of variation are quite high, that is, $52 \mathrm{~cm}$ for height and $72.9 \mathrm{~kg}$ for body mass. The central tendency values found for the echocardiographic parameters show a slight increase in left ventricular cavity diameter $(54.5 \mathrm{~mm})$ for these age groups, suggesting a markedly eccentric profile (LVRPT $=0.28$.

The age-related variation for the entire sample of athletes is shown in Table 2. Understandably, the groups of athletes aged 15 and 16 years had higher mean values for height ( $\mathrm{F}=5.039$; $\mathrm{p}<0.01$; $\mathrm{ES}-\mathrm{r}=0.243)$ and $\mathrm{BSA}(\mathrm{F}=3.984$; $\mathrm{p}<0.05$; ES-r $=0.217$ ). Although this trend also occurs in relation to body mass, the values are not statistically significant. Additionally, in relation to the echocardiographic parameters, those in the groups of 15 and 16 year-old athletes, compared to their 14-year-old peers, had higher means in left ventricular end-diastolic $(F=4.211 ; \mathrm{p}<0.05$; ES-r $=0.223)$ and end-systolic ( $\mathrm{F}=5.215 ; \mathrm{p}<0.01 ; \mathrm{ES}-\mathrm{r}=0.247)$ diameters, as well as IVSW thickness $(F=3.197 ; \mathrm{p}<0.05$; ES-r $=0.195)$. Also, LA diameter $(\mathrm{F}=6.881 ; \mathrm{p}<0.01$; $\mathrm{ES}$ $\mathrm{r}=0.281)$ and $\operatorname{LVM}(\mathrm{F}=4.432$; $\mathrm{p}<0.05$; ES-r=0.228) were higher in the 16 year-old group.

Anthropometric characteristics and echocardiographic variables were sensitive to the type of modality practiced. As expected, basketball players were taller $(\mathrm{F}=23.448$; $\mathrm{p}<0.001$; ES-r $=0.553)$, heavier $(\mathrm{F}=6.702 ; \mathrm{p}<0.001$; $\mathrm{ES}-\mathrm{r}=0.334)$ and had greater BSA $(F=11.896 ; \mathrm{p}<0.001 ; \mathrm{ES}-\mathrm{r}=0.427)$ than 


\begin{tabular}{|c|c|c|c|c|c|c|c|}
\hline \multirow[t]{2}{*}{ Variable } & \multirow{2}{*}{$\begin{array}{l}\text { Unit } \\
\text { measured }\end{array}$} & \multirow[t]{2}{*}{ Abbreviation } & \multicolumn{2}{|l|}{ Amplitude } & \multicolumn{2}{|l|}{ Mean } & \multirow{2}{*}{$\begin{array}{l}\text { Standard } \\
\text { deviation }\end{array}$} \\
\hline & & & Minimum & Maximum & Value & $(95 \mathrm{Cl})$ & \\
\hline Age & years & & 13.31 & 16.66 & 15.28 & $(15.19-15.39)$ & 0.76 \\
\hline Height & $\mathrm{cm}$ & & 143.6 & 195.6 & 172.7 & $(172.1-174.7)$ & 8.4 \\
\hline Body mass & $\mathrm{kg}$ & & 38.4 & 111.3 & 65.2 & $(63.7-67.5)$ & 12.6 \\
\hline Body surface & $\mathrm{m}^{2}$ & BSA & 1.24 & 2.32 & 1.77 & $(1.75-1.81)$ & 0.19 \\
\hline LV end-diastolic diameter & $\mathrm{mm}$ & LVED & 44.2 & 65.0 & 54.9 & $(54.3-55.6)$ & 4.2 \\
\hline LV end-systolic diameter & $\mathrm{mm}$ & LVES & 24.9 & 45.5 & 34.7 & $(34.2-35.3)$ & 3.4 \\
\hline Interventricular end-diastolic septal wall thickness & $\mathrm{mm}$ & IVSW & 5.8 & 10.6 & 8.1 & $(7.9-8.2)$ & 0.8 \\
\hline LV end-diastolic posterior wall thickness & $\mathrm{mm}$ & LVPW & 5.5 & 10.0 & 7.6 & $(7.5-7.7)$ & 0.8 \\
\hline LV ejection fraction & $\%$ & LVEF & 42.0 & 76.0 & 65.4 & $(64.7-66.1)$ & 4.5 \\
\hline LV shortening fraction & $\%$ & LVSF & 29.8 & 45.3 & 36.7 & $(36.2-37.1)$ & 3.1 \\
\hline Aortic root diameter & $\mathrm{mm}$ & AoRD & 19.6 & 34.0 & 27.5 & $(27.1-27.9)$ & 2.7 \\
\hline LA diameter & $\mathrm{mm}$ & LAD & 20.0 & 47.9 & 36.2 & $(35.6-36.9)$ & 4.2 \\
\hline LA diameter:aortic root ratio & $\mathrm{mm} / \mathrm{mm}$ & LAD/AoRD & 0.77 & 2.00 & 1.33 & $(1.30-1.35)$ & 0.17 \\
\hline Left ventricular mass & g & LVM & 83.1 & 258.1 & 157.3 & $(152.1-162.4)$ & 33.6 \\
\hline Left ventricular mass index & $\mathrm{g} / \mathrm{m}^{2}$ & LVMI & 54.6 & 136.1 & 87.9 & $(85.7-90.2)$ & 14.9 \\
\hline LV relative parietal thickness & & LVRPT & 0.22 & 0.36 & 0.29 & $(0.28-0.30)$ & 0.03 \\
\hline
\end{tabular}

Note: 95CI: 95\% confidence interval; LV: left ventricle; LA: left auricle.

TABLE 2 Descriptive statistics (mean \pm standard deviation) and age-related variation for the entire sample of athletes.

\begin{tabular}{|c|c|c|c|c|c|c|c|c|}
\hline & \multirow{2}{*}{$\begin{array}{l}\text { Sub-15 } \\
14.0-14.9 \\
(n=41)\end{array}$} & \multirow{2}{*}{$\begin{array}{l}\text { Sub-16 } \\
15.0-15.9 \\
(n=100)\end{array}$} & \multirow{2}{*}{$\begin{array}{l}\text { Sub-17 } \\
16.0-16.9 \\
(n=23)\end{array}$} & \multirow[t]{2}{*}{$\mathbf{F}$} & \multirow[t]{2}{*}{$\mathbf{p}$} & \multicolumn{2}{|c|}{ Magnitude } & \multirow{2}{*}{$\begin{array}{l}\text { Comparisons } \\
\text { Post hoc* }\end{array}$} \\
\hline & & & & & & ES-r & (qualitative) & \\
\hline Height $(\mathrm{cm})$ & $170.2 \pm 9.5$ & $174.0 \pm 7.3$ & $176.5 \pm 9.2$ & 5.039 & 0.008 & 0.243 & (small) & $\mathrm{S} 17>\mathrm{S} 15 ; \mathrm{S} 16>\mathrm{S} 15$ \\
\hline Body mass (kg) & $62.6 \pm 13.5$ & $65.9 \pm 11.7$ & $69.9 \pm 11.8$ & 2.723 & 0.069 & 0.181 & (small) & \\
\hline Body surface area $\left(\mathrm{m}^{2}\right)$ & $1.72 \pm 0.22$ & $1.79 \pm 0.17$ & $1.85 \pm 0.19$ & 3.984 & 0.020 & 0.217 & (small) & $\mathrm{S} 17>\mathrm{S} 15$ \\
\hline $\operatorname{LVED}(\mathrm{mm})$ & $53.5 \pm 4.4$ & $55.2 \pm 3.8$ & $56.5 \pm 4.5$ & 4.211 & 0.016 & 0.223 & (small) & $\mathrm{S} 17>\mathrm{S} 15 ; \mathrm{S} 16>\mathrm{S} 15$ \\
\hline $\operatorname{LVES}(\mathrm{mm})$ & $33.4 \pm 3.7$ & $35.0 \pm 3.1$ & $36.0 \pm 3.3$ & 5.215 & 0.006 & 0.247 & (small) & $\mathrm{S} 17>\mathrm{S} 15 ; \mathrm{S} 16>\mathrm{S} 15$ \\
\hline IVSW (mm) & $7.8 \pm 1.0$ & $8.1 \pm 0.8$ & $8.2 \pm 0.7$ & 3.197 & 0.044 & 0.195 & (small) & $\mathrm{S} 17>\mathrm{S} 15 ; \mathrm{S} 16>\mathrm{S} 15$ \\
\hline LVPW (mm) & $7.4 \pm 1.0$ & $7.6 \pm 0.7$ & $7.7 \pm 0.8$ & 1.454 & 0.237 & 0.133 & (small) & \\
\hline $\operatorname{LVEF}(\%)$ & $66.2 \pm 6.1$ & $65.1 \pm 4.0$ & $64.9 \pm 4.4$ & 0.865 & 0.423 & 0.103 & (small) & \\
\hline LVSF (\%) & $37.5 \pm 3.4$ & $36.4 \pm 2.9$ & $36.1 \pm 3.4$ & 2.171 & 0.117 & 0.162 & (small) & \\
\hline AoRD (mm) & $26.8 \pm 2.7$ & $27.8 \pm 2.7$ & $27.8 \pm 2.6$ & 2.035 & 0.134 & 0.157 & (small) & \\
\hline LAD $(\mathrm{mm})$ & $34.6 \pm 4.1$ & $36.5 \pm 4.1$ & $38.4 \pm 4.0$ & 6.881 & 0.001 & 0.281 & (small) & $\mathrm{S} 17>\mathrm{S} 16>\mathrm{S} 15$ \\
\hline LAD/AoRD (\%) & $1.30 \pm 0.18$ & $1.32 \pm 0.18$ & $1.39 \pm 0.15$ & 1.865 & 0.158 & 0.150 & (small) & \\
\hline Left ventricular mass (g) & $145.9 \pm 38.5$ & $158.9 \pm 29.8$ & $170.3 \pm 33.6$ & 4.432 & 0.013 & 0.228 & (small) & $\mathrm{S} 17>\mathrm{S} 16>\mathrm{S} 15$ \\
\hline LVMI $\left(\mathrm{g} / \mathrm{m}^{2}\right)$ & $83.8 \pm 14.4$ & $88.8 \pm 14.8$ & $91.5 \pm 13.2$ & 2.544 & 0.082 & 0.175 & (small) & \\
\hline LVRPT & $0.28 \pm 0.03$ & $0.29 \pm 0.02$ & $0.28 \pm 0.02$ & 0.121 & 0.886 & 0.039 & (trivial) & \\
\hline
\end{tabular}

LVED: left ventricular end-diastolic diameter; LVES: left ventricular end-systolic diameter; IVSW: interventricular end-diastolic septal wall thickness; LVPW: left ventricular end-diastolic posterior wall thickness; LVEF: left ventricular ejection fraction; LVSF: left ventricular shortening fraction; AoRD: aortic root diameter; LAD: left auricle's diameter; LAD/AoRD: LA diameter/aortic root ratio; LVMI: left ventricular mass index; LVRPT: left ventricle's relative parietal thickness. 
hockey players, judokas and swimmers. The variation associated with sports modality for echocardiographic parameters was only significant for some variables of cardiac morphology. Basketball players, hockey players and swimmers had higher values for IVSW thickness ( $\mathrm{F}=7.287$; $\mathrm{p}<0.001$; ES- $\mathrm{r}=0.347)$ and LVPW thickness $(\mathrm{F}=8.038$; $\mathrm{p}<0.001$; ES-r $=0.362$ ) compared to the judokas. The same happens in the test of comparison of means having as dependent variables the LVM $(F=7.015$; $p<0.001$; ES$\mathrm{r}=0.341)$ and left ventricular mass index $(\mathrm{F}=9.463 ; \mathrm{p}<0.001$; ES-r $=0.388$ ). Basketball players and hockey players have a larger left atrial cavity, compared to judokas $(\mathrm{F}=3.865$; $\mathrm{p}=0.011$; $\mathrm{ES}-\mathrm{r}=0.316$ ). Finally, the data points to a higher LVRPT in swimmers compared to judokas $(\mathrm{F}=4.127$; $\mathrm{p}=0.008$; ES- $\mathrm{r}=0.268$ ), being swimmers characterized by a markedly eccentric left ventricular profile (Table 3 ). Table 3 also shows the results of covariance analysis. Covariates included: chronological age, stature and body mass, allowing to verify that, in general, the differences between the size of the cavities and thickness of the heart tissue structures, as well as composite measures, confirm the main conclusions previously described. In fact, it suggests that the results found are mainly due to chronic adaptations to the effects of training and competition and not so much to the sport selection factor that associates particular morphological archetypes to each of the modalities, particularly, tall adolescents to basketball. The results presented in Table 3, adjusted for mean values of age equal to 15.30 years, height equal to $173.4 \mathrm{~cm}$ and body mass equal to $65.6 \mathrm{~kg}$, allow us to conclude that judo athletes have less increase in IVSW ( $F=7.876$; $p<0.01$; ES-r=0.362) and LVPW ( $F=9.794 ; p<0.01 ; E S-r=0.397)$ thicknesses. As for the latter variable, after adjustment for age and body size, it is still possible to distinguish swimmers, who present significantly higher values compared to basketball players and hockey players. The smaller dimensional development of a judoka's heart is also noted with respect to the left atrial cavity $(F=3.338 ; p<0.05$; ES-r=0.245). Finally, in agreement with the previous points and after controlling a number of additional effects, the comparison between modalities, with respect to the mean values of the left ventricular mass, presents the swimmers positively and the judokas negatively.

\section{Discussion}

Recognizing the complexity derived from difficulties in distinguishing the effects of sports training, growth and biological maturation, our study analyzed the effects of age and sports modality on the remodeling process of the heart cavities of young athletes in their late teens.
Manolas et al. ${ }^{20}$ refer to this age group as the period of greatest increase in cardiac chambers. In our study, the mean $\mathrm{LV}$ end-diastolic diameter was $1.7 \mathrm{~mm}$ greater in 15 -year-old athletes compared to the mean value determined for athletes at an immediately younger age, i.e., 14 years. Likewise, a mean difference of $1.3 \mathrm{~mm}$ was found between the 15 and 16 year olds, with the highest values among the older athletes. This direct variation between age and measures of LV end-diastolic diameter coincides with the increase in height and body surface of younger adolescents compared to the older ones.

Recently, a longitudinal study ${ }^{21}$ with healthy adolescents aged 11 to 15 years determined that sports participation for $3.1 \pm 1.2$ hours per week plus one match per week was not associated with increased LV growth, after statistical adjustment for individual differences in growth and biological maturation. However, it has been widely accepted that different modalities of physical training result in diverse patterns of cardiac adaptation in athletes. ${ }^{17}$ The association established between anthropometry of the whole body and the generalities of the echocardiographic parameters should also be recognized. ${ }^{21-23}$ It is true that higher values for body size translate into higher values for the dimensions of aortic root, left atrium, ventricular cavities and $\mathrm{LV}$ wall thickness. ${ }^{16}$ Recently, a study with male hockey players aged 14.5 to 16.5 years determined correlations between left ventricular mass and several indicators: 0.36 with chronological age, 0.50 with skeletal age, 0.52 with height, 0.61 with seated height, 0.56 with lean mass. ${ }^{22}$

After organizing the analysis of the means by sports modality, we found that the basketball players were taller, heavier and consequently presented greater body surface compared to their peers in the remaining three sports modalities. In fact, basketball players are recognized and consensually among the groups of athletes with larger body size and are also those with higher values for LA diameter, IVSW and LVPW thickness, LVM and left ventricular mass index..$^{24}$ In this particular aspect, the results of our study are similar to those of Madeira et al., ${ }^{1}$ which also included 15-16 year-old participants. Variations of heart dimensions cannot be attributed solely to the adaptive effect to training.

Based on the results of our study, we found that the judokas presented lower values for IVSW and LVPW thickness, left ventricular mass and mass index in comparison with all other athletes, and an LA diameter lower than that presented by basketball and hockey players. Other studies $^{23}$ that included athletes from a single age group stated that swimmers have smaller ventricular cavities, 
but higher values for IVSW and LVPW thickness compared to young hockey players. Although we have also found a trend towards slightly higher mean values in our study, the differences are not statistically significant.

Swimmers, compared to control groups, often present higher values for cardiac cavity diameters and LV wall thickness. ${ }^{25}$ Future studies should have a mixed longitudinal design with samples derived from a single modality or, desirably, sub-samples extracted from more than one modality, associating measures capable of describing the volume and weekly intensity of training and competitions to the longitudinal predictors. Regarding LVRPT, all modalities studied have a markedly eccentric profile, although in the judokas this profile is significantly more pronounced than in swimmers. While some authors mention that the enlargement of the left atrium is also a component of the athlete's heart, ${ }^{26}$ we did not find significant changes in the other echocardiographic variables between

TABLE 3 Descriptive statistics (mean \pm standard deviation) for the groups of athletes organized by sport modality and

ANOVA to test the variation associated to the modality practiced, followed by ANCOVA with adjustment for age (centered in 15.30 years), height (centered in $173.4 \mathrm{~cm}$ ) and body mass (centered at $65.6 \mathrm{~kg}$ ).

\begin{tabular}{|c|c|c|c|c|c|c|c|c|c|}
\hline & \multirow{2}{*}{$\begin{array}{l}\text { Basketball } \\
(n=42)\end{array}$} & \multirow{2}{*}{$\begin{array}{l}\text { Roller hockey } \\
(n=73)\end{array}$} & \multirow{2}{*}{$\begin{array}{l}\text { Judo } \\
(n=28)\end{array}$} & \multirow{2}{*}{$\begin{array}{l}\text { Swimming } \\
(n=21)\end{array}$} & \multicolumn{2}{|c|}{ ANOVA } & \multicolumn{2}{|c|}{ Magnitude } & \multirow{2}{*}{$\begin{array}{l}\text { Comparisons } \\
\text { Post hoc* }\end{array}$} \\
\hline & & & & & $F$ & $\mathbf{p}$ & ES-r & (qualitative) & \\
\hline Age (years) & $15.32 \pm 0.64$ & $15.29 \pm 0.73$ & $15.23 \pm 0.49$ & $15.35 \pm 0.43$ & 0.147 & 0.931 & 0.053 & (trivial) & \\
\hline Height $(\mathrm{cm})$ & $181.1 \pm 7.8$ & $169.9 \pm 6.9$ & $171.4 \pm 7.4$ & $172.8 \pm 5.0$ & 23.448 & $<0.01$ & 0.553 & (wide) & $\mathrm{B}>\mathrm{H} ; \mathrm{B}>\mathrm{J} ; \mathrm{B}>\mathrm{N}$ \\
\hline Body mass (kg) & $72.4 \pm 11.0$ & $63.9 \pm 11.3$ & $63.6 \pm 16.2$ & $60.7 \pm 6.0$ & 6.702 & $<0.01$ & 0.334 & (moderate) & $\mathrm{B}>\mathrm{H} ; \mathrm{B}>\mathrm{J} ; \mathrm{B}>\mathrm{N}$ \\
\hline $\operatorname{BSA}\left(m^{2}\right)$ & $1.92 \pm 0.17$ & $1.74 \pm 0.17$ & $1.74 \pm 0.23$ & $1.72 \pm 0.09$ & 11.896 & $<0.01$ & 0.427 & & $\mathrm{~B}>\mathrm{H} ; \mathrm{B}>\mathrm{J} ; \mathrm{B}>\mathrm{N}$ \\
\hline LVED $(\mathrm{mm})$ & $56.0 \pm 3.9$ & $55.0 \pm 4.6$ & $53.3 \pm 3.5$ & $55.1 \pm 3.3$ & 2.561 & 0.057 & 0.214 & (small) & \\
\hline LVES (mm) & $35.1 \pm 3.3$ & $35.1 \pm 3.6$ & $33.4 \pm 3.2$ & $34.7 \pm 2.6$ & 1.825 & 0.145 & 0.182 & (small) & \\
\hline IVSW (mm) & $8.2 \pm 0.8$ & $8.1 \pm 0.8$ & $7.5 \pm 0.7$ & $8.4 \pm 0.8$ & 7.287 & $<0.01$ & 0.347 & (moderate) & $B>J ; H>J ; N>J$ \\
\hline LVPW (mm) & $7.8 \pm 0.9$ & $7.6 \pm 0.7$ & $7.0 \pm 0.6$ & $8.0 \pm 0.8$ & 8.038 & $<0.01$ & 0.362 & (moderate) & $B>J ; H>J ; N>J$ \\
\hline LVEF (\%) & $66.9 \pm 4.6$ & $64.5 \pm 4.3$ & $64.9 \pm 6.0$ & $66.0 \pm 3.2$ & 2.710 & 0.057 & 0.220 & (small) & \\
\hline LVSF (\%) & $37.2 \pm 3.5$ & $36.3 \pm 3.1$ & $36.7 \pm 3.2$ & $37.0 \pm 2.4$ & 0.831 & 0.479 & 0.124 & (small) & \\
\hline AoRD $(\mathrm{mm})$ & $28.2 \pm 2.7$ & $27.5 \pm 2.6$ & $26.4 \pm 2.2$ & $27.8 \pm 3.2$ & 2.596 & $<0.05$ & 0.215 & (small) & \\
\hline LAD (mm) & $37.3 \pm 4.4$ & $36.7 \pm 4.5$ & $34.1 \pm 3.6$ & $35.6 \pm 2.8$ & 3.865 & $<0.01$ & 0.260 & (small) & $B>J ; H>J$ \\
\hline LAD/AoRD & $1.33 \pm 0.18$ & $1.34 \pm 0.19$ & $1.30 \pm 0.14$ & $1.30 \pm 0.19$ & 0.723 & 0.540 & 0.116 & (small) & \\
\hline $\operatorname{LVM}(\mathrm{g})$ & $167.5 \pm 35.4$ & $157.5 \pm 32.5$ & $134.3 \pm 23.7$ & $166.6 \pm 29.8$ & 7.015 & $<0.01$ & 0.341 & (moderate) & $B>J ; H>J ; N>J$ \\
\hline $\operatorname{LVMI}\left(\mathrm{g} / \mathrm{m}^{2}\right)$ & $86.8 \pm 13.7$ & $90.2 \pm 14.7$ & $77.1 \pm 8.6$ & $96.5 \pm 14.9$ & 9.463 & $<0.01$ & 0.388 & (moderate) & $B>J ; H>J ; N>J$ \\
\hline \multirow[t]{3}{*}{ LVRPT } & $0.29 \pm 0.03$ & $0.29 \pm 0.02$ & $0.27 \pm 0.03$ & $0.30 \pm 0.03$ & 4.127 & $<0.01$ & 0.268 & (small) & $N>J$ \\
\hline & \multirow{2}{*}{\multicolumn{4}{|c|}{$\begin{array}{l}\text { Adjusted means } \\
\text { (controlled for age, height and body mass) }\end{array}$}} & \multicolumn{2}{|c|}{ ANCOVA } & \multicolumn{2}{|c|}{ Magnitude } & Comparisons \\
\hline & & & & & $\mathbf{F}$ & $\mathbf{P}$ & ES-r & (qualitative) & Post hoc* \\
\hline LVED (mm) & 54.5 & 55.4 & 53.8 & 56.0 & 2.733 & 0.046 & 0.223 & (small) & \\
\hline LVES (mm) & 33.9 & 35.4 & 33.8 & 35.4 & 3.803 & $<0.01$ & 0.260 & (small) & $H>J$ \\
\hline IVSW (mm) & 8.1 & 8.1 & 7.5 & 8.5 & 7.876 & $<0.01$ & 0.362 & (moderate) & $B>J ; H>J ; N>J$ \\
\hline $\operatorname{LVPW}(\mathrm{mm})$ & 7.5 & 7.7 & 7.1 & 8.1 & 9.794 & $<0.01$ & 0.397 & (moderate) & $\mathrm{N}>\mathrm{B} ; \mathrm{H}>\mathrm{J} ; \mathrm{N}>\mathrm{H} ; \mathrm{N}>\mathrm{J}$ \\
\hline LVEF (\%) & 67.6 & 64.2 & 64.6 & 65.8 & 3.635 & $<0.01$ & 0.255 & (small) & $\mathrm{B}>\mathrm{H}$ \\
\hline LVSF (\%) & 37.5 & 36.2 & 36.5 & 36.8 & 1.239 & 0.298 & 0.152 & (small) & \\
\hline AoRD $(\mathrm{mm})$ & 27.2 & 27.9 & 26.7 & 28.0 & 2.135 & 0.098 & 0.198 & (small) & \\
\hline $\operatorname{LAD}(\mathrm{mm})$ & 36.9 & 36.6 & 34.4 & 36.4 & 3.338 & $<0.05$ & 0.245 & (small) & $B>J ; H>J$ \\
\hline LAD/AoRD & 1.36 & 1.32 & 1.29 & 1.32 & 0.777 & 0.509 & 0.121 & (small) & \\
\hline $\operatorname{LVM}(\mathrm{g})$ & 154.5 & 161.1 & 138.5 & 174.5 & 10.576 & $<0.01$ & 0.410 & (moderate) & $\mathrm{N}>\mathrm{B} ; \mathrm{H}>\mathrm{J} ; \mathrm{N}>\mathrm{J}$ \\
\hline LVMI $\left(\mathrm{g} / \mathrm{m}^{2}\right)$ & 86.0 & 90.1 & 77.7 & 98.0 & 10.855 & $<0.01$ & 0.414 & (moderate) & $\mathrm{N}>\mathrm{B} ; \mathrm{H}>\mathrm{J} ; \mathrm{N}>\mathrm{J}$ \\
\hline LVRPT & .29 & .29 & .27 & .30 & 4.013 & $<0.01$ & 0.267 & (small) & $N>J$ \\
\hline
\end{tabular}

Note: Only comparisons with statistically significant differences are identified.

BSA: body surface area; LVED: left ventricular end-diastolic diameter; LVES: left ventricular end-systolic diameter; IVSW: interventricular end-diastolic septal wall thickness; LVPW: left ventricular end-diastolic posterior wall thickness; LVEF: left ventricular ejection fraction; LVSF: left ventricular shortening fraction; AoRD: aortic root diameter; LAD: left auricle's diameter; LAD/AoRD: LA diameter/aortic root ratio; LVM: left ventricular mass; LVMI: left ventricular mass index; LVRPT: left ventricle's relative parietal thickness. 
the groups, so it is possible that there are more differences between athletes and non-athletes than between athletes of different modalities.

The study of systolic function, performed by calculating the shortening and ejection fractions of the left ventricle, confirms the results reported in the literature, ${ }^{27}$ that is, no significant differences were found between groups. This fact demonstrates that the increase of the cavities and the thickness of the walls of the LV represents for the athletes an increase in cardiac performance, without any impairment at functional level, like other (pathological) situations that can progress to increased cardiac dimensions. In this case, the increase in dimensions is due to the sports training and is performed in a harmonic way, in accordance with the proportion with the body weight. ${ }^{28}$

\section{Limitations}

Four sporting modalities have been taken into account, making it difficult to obtain statistically significant results with so many groups. Therefore, it is possible that the choice of only two clearly contrasting modalities would result in greater association. Magnetic resonance imaging is the most appropriate method to determine LVM, although echocardiographic examination is still the most used methodology, particularly in the context of clinical practice and, especially, in the child and adolescent population. Future studies should consider female athletes and other age groups coinciding with periods of greater sporting specialization, i.e., 17-19 years. Variability of measures resulting from echocardiographic examination with measures of body composition should also be considered.

\section{Conclusion}

Briefly, modalities such as basketball and roller hockey tend to attract, respectively, tall and short adolescents, due to different aspects of performance structure, namely airspace dispute in basketball and skills related to fast movements with the ball next to the ground in roller hockey. It seems that differences in cardiac morphology between athletes of different modalities should also be understood in the light of adapting to the chronic effects of exertion. This is supported by the analyzes in our study, both in relation to the treatment of absolute values and the control of additional effects related to age, stature and body mass. The differences found between judokas and swimmers corroborate the effect of the sports modalities on the process of cardiac remodeling. While the judokas practice an acyclic modality, with great peripheral resistance and less development of ventricular mass, cavities and walls of the ventricle, swimmers are exposed to cyclical movements facilitating the ejection fraction and cardiovascular return. Swimmers training and competition loads are also characterized by less intermittent heart rate regimens, which contributes to the existence of higher mean values both for cardiac mass and cavities, and thickness of the walls limiting them.

\section{ACKNOWLEDGMENTS}

The authors thank the coaches in charge of the national and district teams, national training centers, athletes, and those responsible for the athletes' education, for their willingness to participate in our study. In addition, special thanks are due to the young researcher Filipe Simões (deceased on $02 / 22 / 2013$ ), who participated in the collection of data and, although he did not write the article, he was mainly concerned with the data of the echocardiographic evaluation. Three authors of our study received grants from the Foundation for Science and Technology [JC: SFRH/PROTEC/67972/2010; JVS: SFRH/ BPD/100470/2014; JPMD: SFRH/BD/101083/2014]. Data collection from the basketball athletes was partially supported by the Foundation for Science and Technology [PTDC/DES/70918/2006]. CIDAF has the FCT register uid/dtp/04213/2016.

\section{Conflict of interest}

The authors declare no conflict of interest.

\section{Resumo}

Indicadores de remodelagem cardíaca em atletas adolescentes

Objetivo: Os efeitos decorrentes da prática de diferentes modalidades desportivas resultam em padrões divergentes de adaptação cardíaca. A presente pesquisa procura estudar a variação da morfologia do coração associada a um conjunto de modalidades desportivas distintas quanto à natureza do esforço e aos modelos de preparação, incluindo metodologias de treino e sistemas de competição.

Método: Foram estudados 42 basquetebolistas, 73 hoquistas, 28 judocas e 21 nadadores. A antropometria foi avaliada por um único e experiente antropometrista e os exames ecocardiográficos foram realizados pelo mesmo operador. Recorreu-se à análise da variância para estudar a variação associada a idade, medidas de tamanho corporal e parâmetros ecocardiográficos, bem como para a comparação entre os atletas de diferentes modalidades desportivas.

Resultados: Os basquetebolistas são os atletas mais altos $(\mathrm{F}=23,448 ; \mathrm{p}<0,001 ; \mathrm{ES}-\mathrm{r}=0,553)$, mais pesados $(\mathrm{F}=6,702$; 
$\mathrm{p}<0,001$; ES-r $=0,334)$, com maior superfície corporal $(\mathrm{F}=11,896 ; \mathrm{p}<0,001 ; \mathrm{ES}-\mathrm{r}=0,427)$ e, com os hoquistas, apresentam um diâmetro da aurícula esquerda superior ao dos judocas $(\mathrm{F}=3,865 ; \mathrm{p}=0,011 ; \mathrm{ES}-\mathrm{r}=0,316)$. A espessura telediastólica do septo interventricular $(\mathrm{F}=7,287 ; \mathrm{p}<0,001$; ES-r $=0,347)$ e da parede posterior do ventrículo esquerdo $(\mathrm{F}=8,038 ; \mathrm{p}<0,001 ; \mathrm{ES}-\mathrm{r}=0,362)$ dos judocas é inferior à dos outros atletas, mesmo quando controlado para o tamanho corporal. Os nadadores apresentam uma espessura parietal relativa do ventrículo esquerdo superior à dos judocas ( $\mathrm{F}=4,127$; $\mathrm{p}=0,008$; ES-r=0,268).

Conclusão: As diferentes fontes de variação da morfologia cardíaca prendem-se com as dinâmicas do processo de treino, competição e correspondentemente com os mecanismos adaptativos, sobrepondo-se ao processo de formação desportiva a longo prazo.

Palavras-chave: modalidades desportivas, jovens atletas, ecocardiografia, massa do ventrículo esquerdo, tamanho corporal, crescimento.

\section{References}

1. Madeira RB, Trabulo M, Alves F, Pereira JG. Effects of chronic exercise training on left ventricular dimensions and function in young athletes. Rev Port Cardiol. 2008; 27(7-8):909-22.

2. Naylor LH, George K, O'Driscoll G, Green DJ. The athlete's heart: a contemporary appraisal of the 'Morganroth hypothesis'. Sports Med. 2008; 38(1):69-90.

3. Sagiv M, Sagiv M, Ben-Sira D. Weight lifting training and left ventricular function in adolescent subjects. J Sports Med Phys Fitness. 2007; 47(3):329-34

4. Morganroth J, Maron BJ, Henry WL, Epstein SE. Comparative left ventricular dimensions in trained athletes. Ann Intern Med. 1975; 82(4):521-4.

5. Wernstedt P, Sjöstedt C, Ekman I, Du H, Thuomas KA, Areskog NH, et al. Adaptation of cardiac morphology and function to endurance and strength training. A comparative study using MR imaging and echocardiography in males and females. Scand J Med Sci Sports. 2002; 12(1):17-25.

6. Gates PE, George KP, Campbell IG. Concentric adaptation of the left ventricle in response to controlled upper body exercise training. J Appl Physiol. 2003; 94:549-54.

7. Ben Abdelkrim N, El Fazaa S, El Ati J. Time-motion analysis and physiological data of elite under-19-year-old basketball players during competition. $\mathrm{Br} \mathrm{J}$ Sports Med. 2007; 41(2):69-75.

8. Bonafonte LF, Pérez JR, Marrero RM. Physiological characteristics of rollerhockey: Study in the sports field. Arch Med Dep. 1994; 11(44):345-50.

9. Coelho-e-Silva MJ, Vaz V, Simoes F, Carvalho HM, Valente-Dos-Santos J, Figueiredo AJ, et al. Sport selection in under-17 male roller hockey. J Sports Sci. 2012; 30(16):1793-802.
10. Mitchell JH, Haskell W, Snell P, Van Camp SP. Task Force 8: classification of sports. J Am Coll Cardiol. 2005; 45(8):1364-7.

11. Ullrich B, Pelzer T, Oliveira S, Pfeiffer M. Neuromuscular responses to shortterm resistance training with traditional and daily undulating periodization in adolescent elite judoka. J Strength Cond Res. 2016; 30(8):2083-99.

12. Epstein ML, Goldberg SJ, Allen HD, Konecke L, Wood J. Great vessel, cardiac chamber, and wall growth patterns in normal children. Circulation. 1975 ; 51(6):1124-9.

13. Zdravkovic M, Perunicic J, Krotin M, Ristic M, Vukomanovic V, Soldatovic I, et al. Echocardiographic study of early left ventricular remodeling in highly trained preadolescent footballers. J Sci Med Sport. 2010; 13(6):602-6.

14. Lohman TG, Roche AF, Martorell R. Anthropometric standardization reference manual. Champaign: Human Kinetics; 1988.

15. Slaughter MH, Lohman TG, Boileau RA, Horswill CA, Stillman RJ, Van Loan $\mathrm{MD}$, et al. Skinfold equations for estimation of body fatness in children and youth. Hum Biol. 1988; 60(5):709-23.

16. Pelliccia A, Di Paolo FM, Maron BJ. The athlete's heart: remodeling, electrocardiogram and preparticipation screening. Cardiol Rev. 2002; 10(2):85-90.

17. Basavarajaiah S, Boraita A, Whyte G, Wilson M, Carby L, Shah A, et al. Ethnic differences in left ventricular remodeling in highly-trained athletes relevance to differentiating physiologic left ventricular hypertrophy from hypertrophic cardiomyopathy. J Am Coll Cardiol. 2008; 51(23):2256-62.

18. Lang RM, Bierig M, Devereux RB, Flachskampf FA, Foster E, Pellikka PA, et al. Recommendations for chamber quantification. Eur J Echocardiogr. 2006; 7(2):79-108.

19. Devereux RB, Alonso DR, Lutas EM, Gottlieb GJ, Campo E, Sachs I, et al. Echocardiographic assessment of left ventricular hypertrophy: comparison to necropsy findings. Am J Cardiol. 1986; 57(6):450-8

20. Manolas VM, Pavlik G, Bánhegyi A, Faludi J, Sidó Z, Olexó Z. Echocardiographic changes in the development of the athlete' s heart in 9 to 20-year-old male subjects. Acta Physiol Hung. 2001; 88(3-4):259-70.

21. Valente-Dos-Santos J, Coelho-e-Silva MJ, Castanheira J, Machado-Rodrigues AM, Cyrino ES, Sherar LB, et al. The effects of sports participation on the development of left ventricular mass in adolescent boys. Am J Hum Biol. 2015; 27(4):530-7.

22. Valente-Dos-Santos J, Coelho-e-Silva MJ, Vaz V, Figueiredo AJ, Castanheira J, Leite $\mathrm{N}$, et al. Ventricular mass in relation to body size, composition, and skeletal age in adolescent athletes. Clin J Sport Med. 2013; 23(4):293-9.

23. Valente-Dos-Santos J, Coelho-e-Silva MJ, Ferraz A, Castanheira J, Ronque ER, Sherar LB, et al. Scaling left ventricular mass in adolescent boys aged 11-15 years. Ann Hum Biol. 2014; 41(5):465-8.

24. Corrado D, Pelliccia A, Bjørnstad HH, Vanhees L, Biffi A, Borjesson M, et al. Cardiovascular pre-participation screening of young competitive athletes for prevention of sudden death: proposal for a common European protocol. Consensus Statement of the Study Group of Sport Cardiology of the Working Group of Cardiac Rehabilitation and Exercise Physiology and the Working Group of Myocardial and Pericardial Diseases of the European Society of Cardiology. Eur Heart J. 2005; 26(5):516-24.

25. Triposkiadis F, Ghiokas S, Skoularigis I, Kotsakis A, Giannakoulis I, Thanopoulos V. Cardiac adaptation to intensive training in prepubertal swimmers. Eur J Clin Invest. 2002; 32(1):16-23.

26. D’Ascenzi F, Cameli M, Lisi M, Zacà V, Natali B, Malandrino A, et al. Left atrial remodelling in competitive adolescent soccer players. Int J Sports Med. 2012; 33(10):795-801.

27. Hoogsteen J, Hoogeveen A, Schaffers H, Wijn PF, van Hemel NM, van der Wall EE. Myocardial adaptation in different endurance sports: an echocardiographic study. Int J Cardiovasc Imaging. 2004; 20(1):19-26.

28. Dickhuth HH, Roecker K, Niess A, Hipp A, Heitkamp HC. The echocardiographic determination of volume and muscle mass of the heart. Int J Sports Med. 1996; 17(Suppl 3):S132-9. 